\title{
A novel bacteriochlorin-styrylnaphthalimide conjugate for simultaneous photodynamic therapy and fluorescence imaging $\dagger$
}

\author{
Pavel A. Panchenko, (D) *ab Mikhail A. Grin, ${ }^{c}$ Olga A. Fedorova, (D) ab \\ Marina A. Zakharko, (D) a Dmitriy A. Pritmov, ${ }^{C}$ Andrey F. Mironov, ${ }^{c}$ \\ Antonina N. Arkhipova, ${ }^{a}$ Yuri V. Fedorov, (D) a Gediminas Jonusauskas, (D) d \\ Raisa I. Yakubovskaya, ${ }^{e}$ Natalia B. Morozova, ${ }^{e}{ }^{e}$ Anastasia A. Ignatova ${ }^{f g}$ and \\ Alexey V. Feofanov ${ }^{\mathrm{fg}}$
}

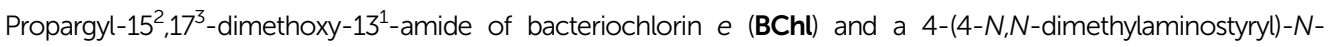
alkyl-1,8-naphthalimide bearing azide group in the $N$-alkyl fragment were conjugated by the copper(I)-catalyzed 1,3-dipolar cycloaddition to produce a novel dyad compound BChl-NI for anticancer photodynamic therapy (PDT) combining the modalities of a photosensitizer (PS) and a fluorescence imaging agent. A precise photophysical investigation of the conjugate in solution using steady-state and time-resolved optical spectroscopy revealed that the presence of the naphthalimide (NI) fragment does not decrease the photosensitizing ability of the bacteriochlorin (BChl) core as compared with $\mathbf{B C h l}$; however, the fluorescence of naphthalimide is completely quenched due to resonance energy transfer (RET) to $\mathbf{B C h l}$. It has been shown that the $\mathbf{B C h l - N I}$ conjugate penetrates into human lung adenocarcinoma A549 cells, and accumulates in the cytoplasm where it has a mixed granular-diffuse distribution. Both $\mathbf{N I}$ and $\mathbf{B C h l}$ fluorescence in vitro provides registration of bright images showing perfectly intracellular distribution of $\mathbf{B C h l - N I}$. The ability of $\mathbf{N I}$ to emit light upon excitation in imaging experiments has been found to be due to hampering of RET as a result of photodestruction of the energy acceptor BChl unit. Phototoxicity studies have shown that the BChl-NI conjugate is not toxic for A549 cells at tested concentrations $(<8 \mu \mathrm{M})$ without light-induced activation. At the same time, the concentrationdependent killing of cells is observed upon the excitation of the bacteriochlorin moiety with red light that occurs due to reactive oxygen species formation. The presented data demonstrate that the $\mathbf{B C h l}-\mathbf{N I}$ conjugate is a promissing dual function agent for cancer diagnostics and therapy.
\end{abstract}

\footnotetext{
${ }^{a}$ A. N. Nesmeyanov Institute of Organoelement Compounds of Russian Academy of Sciences, 119991, Vavilova str. 28, Moscow, Russia. E mail: pavel@ineos.ac.ru; Fax: +7 49913550 85; Tel: +7 4991358098

${ }^{b}$ D. Mendeleev University of Chemical Technology of Russia, 125047, Miusskaya sqr. 9, Moscow, Russia

${ }^{c}$ Moscow Technological University, Institute of Fine Chemical Technologies, 119571, Prospect Vernadskogo, 86, Moscow, Russia

${ }^{d}$ Laboratoire Ondes et Matière d'Aquitaine, UMR CNRS 5798, Bordeaux University, 33405, 351 Cours de la Libération, Talence, France

${ }^{e}$ P. Hertsen Moscow Oncology Research Institute Branch of the National Medical Research Radiological Centre of the Ministry of Health of the Russian Federation, 125284, 2nd Botkinskiy pr. 3, Moscow, Russia

${ }^{f}$ Biological Faculty, Lomonosov Moscow State University, 119992, Leninskie Gory 1, Moscow, Russia

${ }^{g}$ Shemyakin Ovchinnikov Institute of Bioorganic Chemistry of Russian Academy of Sciences, 117997, 16/10, Miklukho Maklaya str., Moscow, Russia
}

\section{Introduction}

Photodynamic therapy (PDT) has emerged as an important treatment modality for a variety of cancers in recent years. ${ }^{1,2}$ PDT involves three necessary components: light, a photosensitizer (PS), and tissue molecular oxygen. Upon irradiation by light of appropriate wavelength, the PS is promoted to a short lived singlet state which rapidly converts to the excited triplet state $\left({ }^{3} \mathrm{PS}^{*}\right)$ through the process of intersystem crossing. Then, ${ }^{3} \mathrm{PS}^{*}$ transfers its excess energy to nearby $\mathrm{O}_{2}$ molecules to form reactive oxygen species such as singlet oxygen $\left({ }^{1} \mathrm{O}_{2}\right)$ and free radicals, which are toxic to malignant cells and tissues. ${ }^{3-6}$

Among various photosensitizing agents, porphyrin-based compounds possess unique advantages related to their ability to be retained in tumors and to produce cytotoxic singlet oxygen. Photofrin, a porphyrin-type PS of the first generation, has achieved some clinical efficacy, but at the same time it suffered from several drawbacks such as chemical heterogeneity, low 
depth of tissue treatment caused by limited light penetration due to the absorption wavelength $(630 \mathrm{~nm})$ laying outside the "phototherapeutic window" (650-1350 nm), a low molar extinction coefficient at $630 \mathrm{~nm}$, and prolonged cutaneous photosensitivity caused by its slow elimination in normal tissue. ${ }^{7}$ Compared to porphyrins, chlorin- and bacteriochlorin-type PSs in which one or two pyrrole units (diagonal to each other) are reduced respectively exhibit intense absorption in the near infrared region $(\geq 650 \mathrm{~nm}$ ), relatively low dark toxicities, rapid clearance from normal tissue and low cutaneous phototoxicity. ${ }^{8-13}$ Despite smaller synthetic availability, di- and tetrahydroporphyrins could be considered as some of the most promising candidates for creating efficient second-generation drugs for PDT of cancer.

An important characteristic of most of the porphyrin-based photosensitizers is their ability to fluoresce. This property has been extensively explored in pre-clinical and clinical studies for fluorescence-image guided PDT. Unfortunately, porphyrins, chlorins, and bacteriochlorins display a small Stokes shift between their longer wavelength absorption and emission bands ${ }^{14-16}$ and, therefore, their fluorescence is difficult to filter out of the scattered excitation light. This property of the PS fluorescence complicates imaging of deeply seated and large tumors. On the other hand, excitation of the porphyrin-based photosensitizer ultimately leads to the production of reactive oxygen species and related toxicity. ${ }^{14-17}$

To overcome this difficulty a new approach which consists of the construction of bifunctional systems combining modalities of a PS and a diagnostic agent (so called theranostics) has been developed. ${ }^{18-22}$ In such systems, a fluorescent moiety can be excited selectively and independently from the photosensitizer unit enabling fluorescence imaging without toxic effects. Thus, Pandey and coworkers have used cyanine dyes as fluorescent labels to prepare conjugates with PSs. ${ }^{18-20}$ A distinct feature of the emission spectra of cyanine dyes is that their fluorescence can easily reach the near-infrared (NIR) region upon increasing the length of the polymethine chain. ${ }^{23}$ However, polymethine cyanine dyes are not so easy to synthesize and to modify, their photo-stabilities are relatively low and their Stokes shift is usually less than $25 \mathrm{~nm}$, which may cause self-quenching as well as the increase of measurement error due to detection of scattered excitation, thus decreasing the detection sensitivity to a great extent as it is in the case of using simple porphyrin sensitizers. Some examples of BODIPY-phthalocyanine (24,25 $^{2}$ and rhodamine-phthalocyanine $e^{26,27}$ conjugates have also been described in the literature. Despite the higher photostability of BODIPY and rhodamine derivatives as compared with cyanine dyes, these types of fluorophores also demonstrate a small difference between absorption and emission maxima. Therefore, NIR dyes with a larger Stokes shift are very promising for the development of bifunctional conjugates for simultaneous photodynamic therapy and fluorescence imaging.

1,8-Naphthalimide derivatives are famous organic fluorophores which generally exhibit high thermo- and photostability and are known to act as fluorescent brighteners and dyes for polymer fibers, ${ }^{28,29}$ laser active media, ${ }^{30,31}$ electroluminescent materials $^{32-34}$ and optical memory devices. ${ }^{35-37}$ Because of its intense fluorescence, large Stokes shifts along with the relative ease of synthetic operations for targeted modification of the molecular structure, these types of compounds have found application in the construction of fluorescent chemosensors for biologically relevant cations and anions, ${ }^{38-40}$ labels or probes for proteins, cells, lysosomes and other acidic organelles. ${ }^{41-43}$ In our recent papers, ${ }^{44-46}$ we have described photophysical properties of naphthalimides containing a substituted styryl fragment as an electron releasing group at the $4^{\text {th }}$ position of a naphthalene ring. It has been found that the presence of the 4 - $(N, N$-dimethylamino)styryl group extends the $\pi$-system of the parent chromophore and results in the long wavelength intramolecular charge transfer (ICT) absorption and emission, which is preferable for fluorescence imaging. Herein, we report on the synthesis, spectroscopic investigation and evaluation of PDT activity of the novel conjugate of a bacteriochlorin photosensitizer and 4-(N,N-dimethylamino)styryl-1,8-naphthalimide (BChl-NI, Scheme 1). The results and experimental details of our study of optical properties of this molecular system in solution and in living cells are presented. We report on the distinct photoinduced cytotoxicity of BChl-NI for human adenocarcinoma A549 cells as well as magenta-to-red conversion of BChl-NI fluorescence that can be useful to control the integrity of the photosensitizer moiety during irradiation of cancer cells.

\section{Experimental procedures}

\section{Synthesis of the BChl-NI conjugate}

For the synthesis of BChl-NI, we used the well-known copper(I)catalyzed click reaction of 1,3-dipolar cycloaddition between naphthalimide-containing alkylazide NI6 and the triple bond derivative of bacteriochlorin $e$ BChl (Scheme 1). The latter was afforded from the methyl ester of bacteriopheophorbide $a$ BPheid and propargylamine. Preparation of BPheid starting from biomass Rhodobacter capsulatus was carried out according to the described method. ${ }^{47,48}$ The first step of the synthesis of naphthalimide NI6, in which the commercial starting material 4-bromo-1,8-naphthalic anhydride was reacted with ethanolamine, was performed conveniently in EtOH at reflux. ${ }^{49} \mathrm{Next}$, 4-bromnaphthalimide NI1 was subjected to the Heck coupling reaction with $4-N, N$-dimethylaminostyrene under the catalyst $\mathrm{Pd}(\mathrm{OAc})_{2}{ }^{50}$ followed by the nucleophilic substitution of hydroxyl by the azide group in the hydroxyethyl fragment via subsequent treatment with $\mathrm{POCl}_{3}$ and $\mathrm{NaN}_{3}$. Details of synthetic procedures and identifications are shown in the ESI. $\dagger$ The synthesis of $N$-butyl-4-styrylnaphthalimide NI4 which was used for a comparative analysis of spectral characteristics has been described earlier. $^{44}$

\section{Steady-state optical measurements}

The absorption spectra were taken on a Varian-Cary 5G spectrophotometer. The fluorescence quantum yield measurements were performed using a Varian-Cary 5G spectrophotometer and a FluoroLog-3 spectrofluorometer. Spectral measurements were carried out in air-saturated acetonitrile solutions 

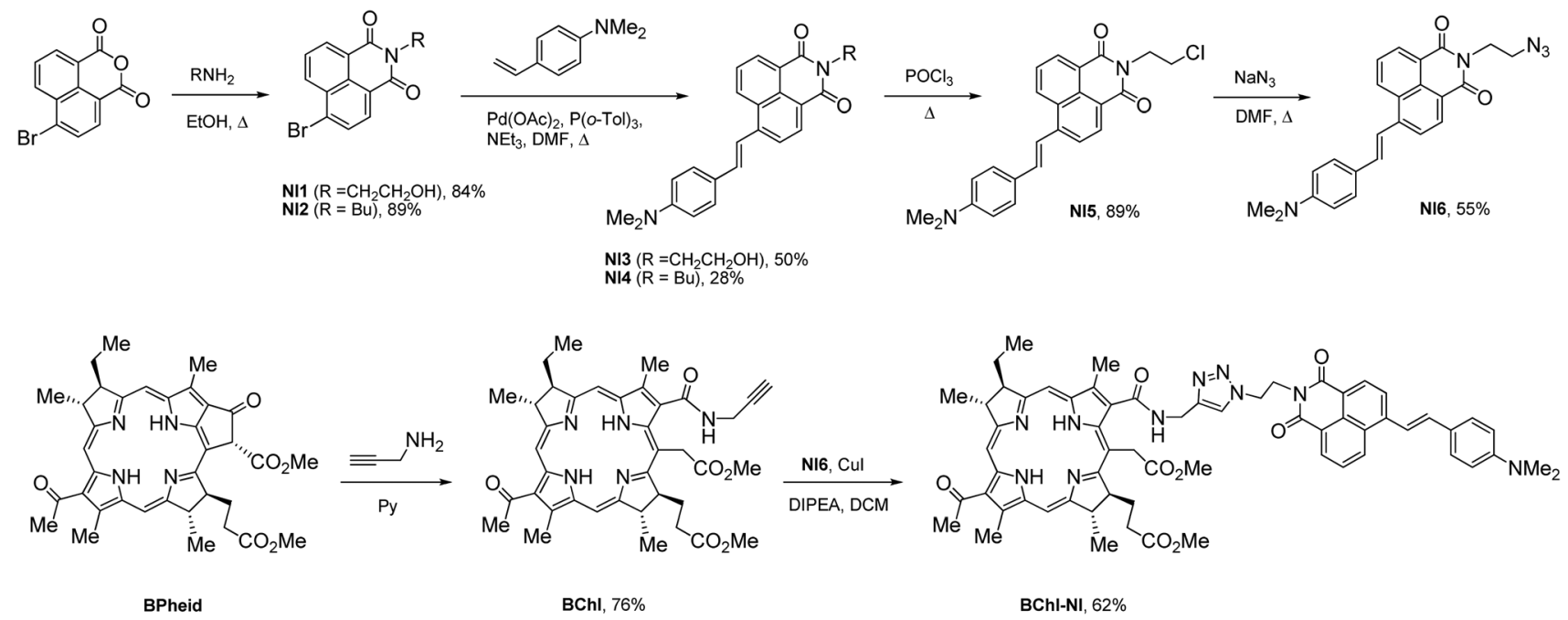

Scheme 1 Synthesis of BChl, NI1-6 and BChl-NI.

(acetonitrile of spectrophotometric grade, water content $<0.005 \%$, Aldrich) at $20 \pm 1{ }^{\circ} \mathrm{C}$; the concentrations of the studied compounds were about $0.5-2.0 \times 10^{-5} \mathrm{M}$. All measured fluorescence spectra were corrected for the nonuniformity of detector spectral sensitivity. Coumarin 481 in acetonitrile $\left(\varphi^{\mathrm{fl}}=0.08\right)^{51}$ was used as a reference for the fluorescence quantum yield measurements. The fluorescence quantum yields were calculated by eqn (1), ${ }^{52}$

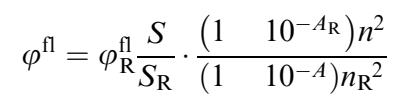

wherein $\varphi^{\mathrm{fl}}$ and $\varphi_{\mathrm{R}}^{\mathrm{fl}}$ are the fluorescence quantum yields of the studied solution and the standard compound, respectively; $A$ and $A_{\mathrm{R}}$ are the absorption of the studied solution and the standard respectively; $S$ and $S_{\mathrm{R}}$ are the areas underneath the curves of the fluorescence spectra of the studied solution and the standard respectively; and $n$ and $n_{\mathrm{R}}$ are the refraction indices of the solvents for the substance under study and the standard compound.

\section{Quantum yields of singlet oxygen generation}

The quantum yields of singlet oxygen $\left(\Phi_{\Delta}\right)$ were estimated in acetone by using tetraphenylporphyrin (TPP) as a reference compound $\left(\Phi_{\Delta}^{\mathrm{TPP}}=0.7\right)^{53,54}$ and 1,3-diphenylisobenzofuran (DPBF) as an ${ }^{1} \mathrm{O}_{2}$ trap. In a typical experiment, solutions $(2.5 \mathrm{ml})$ containing both PSs (TPP and PS under study) and DPBF were placed into $1 \mathrm{~cm}$ rectangular spectroscopic cells and irradiated with monochromatic light $(510 \mathrm{~nm})$ using the excitation unit (a xenon lamp and excitation monochromator) of a FluoroLog-3 fluorometer. The initial concentration of DPBF corresponded to the absorption of about 1 at $414 \mathrm{~nm}(\sim 40 \mathrm{mM})$. Identical initial DPBF concentrations were used for the reference solution of TPP and the samples. The change in DPBF absorption at $414 \mathrm{~nm}$ was recorded as a function of irradiation time via UV/Vis spectrometry. The values of $\Phi_{\Delta}$ were calculated by eqn (2),

$$
\Phi_{\Delta}=\Phi_{\Delta}^{\mathrm{R}} \frac{V}{V_{\mathrm{R}}} \cdot \frac{1}{1} 10^{-A_{\mathrm{R}}}
$$

wherein $V$ and $V_{\mathrm{R}}$ are the bleaching rates of the solutions containing PS under study $(V)$ and the reference compound $\left(V_{\mathrm{R}}\right)$ which were found from the slopes of linear plots of absorption at $414 \mathrm{~nm}$ versus irradiation time; $A$ and $A_{\mathrm{R}}$ are absorption values at an excitation wavelength $(510 \mathrm{~nm})$ of the solutions containing studied PS and the reference compound (TPP), respectively. The accuracy of $\Phi_{\Delta}$ estimation was about $10 \%$.

\section{Subpicosecond transient absorption setup}

A Ti:sapphire laser system output $(0.6 \mathrm{~mJ}$ and $30 \mathrm{fs}$ at $800 \mathrm{~nm}$ and $1 \mathrm{kHz}$ pulse repetition rate (Femtopower Compact Pro)) was split in two parts, producing the pump and the probe beams. $80 \%$ of pulses were used to pump an optical parametric generator (TOPAS (Light Conversion)) to generate the wavelength tuneable pump pulse. Following TOPAS, the harmonic generation or frequency mixing in a nonlinear crystal produced the excitation pulses in the range $250-2600 \mathrm{~nm}$. The probe was a white light continuum pulse, extending from $390 \mathrm{~nm}$ to $900 \mathrm{~nm}$, generated by focusing the $800 \mathrm{~nm}$ pulses $(\sim 5 \mu \mathrm{J}$ per pulse) into a $5 \mathrm{~mm}$ thick $\mathrm{D}_{2} \mathrm{O}$ cell. The variable delay time between excitation and probe pulses was obtained by using a delay line with $0.1 \mathrm{~mm}$ resolution. The solutions were placed in a $1 \mathrm{~mm}$ circulating cell. A whitelight signal and reference spectra were recorded using a two-channel fiber spectrometer (Avantes Avaspec-2048-2). A home-written acquisition and experiment-control program in LabView made it possible to record transient spectra with an average error of less than $10^{-3}$ of O.D. The temporal resolution of our setup was better than 60 fs. Temporal chirp of the probe pulse was corrected using a computer program with respect to a Lawrencian fit of a Kerr signal generated in a $0.2 \mathrm{~mm}$ glass plate used in place of the sample.

\section{Nanosecond transient absorption setup}

A frequency tripled Nd:YAG amplified laser system (30 ps, 30 mJ@1064 nm, 20 Hz, Ekspla model PL 2143) output was used to pump an optical parametric generator (Ekspla model PG 401) producing tunable excitation pulses in the range 410-2300 $\mathrm{nm}$. 
The residual fundamental laser radiation was focused in a high pressure Xe filled breakdown cell where a white light pulse for sample probing was produced. All signals were analyzed using a spectrograph (Princeton Instruments Acton model SP2300) coupled with a high dynamic range streak camera (Hamamatsu C7700, 1 ns-1 ms). Accumulated sequences (sample emission, probe without and with excitation) of pulses were recorded and treated with HPDTA (Hamamatsu) software to produce twodimentional maps (wavelength versus delay) of transient absorption intensity in the range $300-800 \mathrm{~nm}$. The typical measurement error was better than $10^{-3}$ O.D.

\section{Fluorescence imaging and procedure of photodynamic treatment of tumor cells}

Human lung adenocarcinoma A549 cells were grown $\left(37{ }^{\circ} \mathrm{C}\right.$, $5 \% \mathrm{CO}_{2}$ ) in Eagle's minimum essential medium with phenol red, $8 \%$ fetal calf serum, $2 \mathrm{mM}$ L-glutamine (so called complete medium). The cells were subcultured twice per week. On the day prior to an experiment, exponentially growing cells were plated on round cover glasses placed in 24-well plates (for microscopic experiments) or seeded directly in 96-well plates (for cytotoxicity measurements). The sowing density was $5 \times 10^{4}$ cells per $\mathrm{ml}$.

For microscopic experiments cells were incubated with 1-8 $\mu \mathrm{M}$ of the BChl-NI conjugate for $1-3 \mathrm{~h}$ in a complete medium at $37{ }^{\circ} \mathrm{C}$. Detailed intracellular distribution of the conjugate was studied using a Leica SP2 confocal laser scanning microscope (Leica, Germany). Conjugate fluorescence was excited with $488 \mathrm{~nm}$ (fits well to the absorption band of the NI chromophore) and $514 \mathrm{~nm}$ (fits well to the absorption band of the BChl chromophore) light. An emission in the 500-600 nm spectral range corresponding to the NI unit was registered using a photomultiplier. An emission in the range 730-1000 nm corresponding to PS was registered using a highly sensitive avalanche photodiode.

Intracellular formation of photoinduced reactive oxygen species (ROS) was measured using $2^{\prime}, 7^{\prime}$-dichlorofluorescein diacetate (DCFDA). Cells were incubated with $1 \mu \mathrm{M}$ BChl-NI for $3 \mathrm{~h}$ and during last $30 \mathrm{~min}$ with $25 \mu \mathrm{M}$ DCFDA. Then cells were irradiated $\left(22 \pm 2 \mathrm{~mW} \mathrm{~cm}^{-2}\right)$ with a halogen lamp $(500 \mathrm{~W})$ through a water filter (thickness of $5 \mathrm{~cm}$ ) and a band-pass filter (transmission 660-1000 nm) for $15 \mathrm{~min}$ and analyzed by confocal microscopy. Fluorescence was excited with $488 \mathrm{~nm}$ and registered in the 500-540 $\mathrm{nm}$ (DCFDA) and 600-650 $\mathrm{nm}$ (NI) regions. Cells incubated with DCFDA and BChl-NI without irradiation as well as cells incubated with BChl-NI and irradiated without DCFDA were used as control.

To clarify the cellular mechanisms of BChl-NI transport, cells were thoroughly washed with a warm medium $\left(37^{\circ} \mathrm{C}\right)$ without serum, pre-incubated with chlorpromazine ( $30 \mu \mathrm{M}$ for $30 \mathrm{~min})$, or methyl- $\beta$-cyclodextrin ( $4 \mathrm{mM}$ for $30 \mathrm{~min}$ ) in a serum-deprived medium $\left(37^{\circ} \mathrm{C}\right)$ and further incubated in the presence of BChl-NI (4 $\mathrm{MM}$ for $70 \mathrm{~min}$ ) at $37{ }^{\circ} \mathrm{C}$. To study the influence of temperature, cells were incubated with BChl-NI $(4 \mu \mathrm{M}$ for $70 \mathrm{~min})$ at $8{ }^{\circ} \mathrm{C}$.

In the confocal microscopy measurements, lateral and axial resolutions were $c a .0 .2$ and $1.5 \mu \mathrm{m}$, respectively. Confocal microspectroscopy studies were performed at $488 \mathrm{~nm}$ excitation using an experimental setup described elsewhere. ${ }^{55}$
For cell survival studies, the BChl-NI conjugate was added to cells (0.04-8 $\mu \mathrm{M}$ with a two-fold increment). Control cells were incubated with equivalent concentrations of Cremophor EL. The cytotoxicity was estimated after incubation of cells with the conjugate or Cremophor EL alone for $6 \mathrm{~h}$ in the dark. The photoinduced cytotoxicity was measured on cells incubated with the conjugate or Cremophor EL alone for $3 \mathrm{~h}$ and irradiated as described above. After irradiation the cells were further incubated for $3 \mathrm{~h}$ and examined for viability. All the experiments were performed in duplicate. To evaluate cell viability, cells were stained with Hoechst 33342 (stains all cells) and propidium iodide (stains dead cells) and analyzed using a fluorescence microscope as described elsewhere. ${ }^{56,57}$ Irradiation of control cells without BChl-NI did not induce any cytotoxicity under the irradiation conditions used.

\section{Results and discussion}

\section{Steady-state spectroscopic properties}

Absorption and emission characteristics of the BChl-NI conjugate and monochromophoric derivatives BChl and NI4 are presented in Fig. 1 and Table 1. As can be seen from Fig. 1a and c, the absorption spectrum of BChl-NI shows the presence of four bands with maxima at 354, 481, 515 and $747 \mathrm{~nm}$ corresponding to the electronic transitions in naphthalimide $(481 \mathrm{~nm})$ and bacteriochlorin (354, 515 and $747 \mathrm{~nm}$ ) moieties. Although the position and intensity of characteristic Q and Soret bands of the bacteriochlorin core in the conjugate are essentially the same as those in the equimolar mixture of BChl and NI4 (Fig. 1c), naphthalimide ICT absorption is observed at slightly higher wavelengths. This red shift could be attributed to the incorporation of an electron withdrawing triazole group in the $N$-butyl substituent of compound NI4, which enhances the ICT.

Fluorescence emission maxima of BChl and NI4 appear at close $\lambda$ values, however, the naphthalimide spectrum is much more broad and substantially drops into the IR region (Fig. 1b). In the case of equimolar mixture, excitation with $460 \mathrm{~nm}$ light which is mostly absorbed by NI4 results in the emission band having the same feature as that of the individual naphthalimide dye but interfered with to some extent by the sharp collateral peak of the BChl fluorescence (Fig. 1d). Interestingly, the spectrum of the BChl-NI conjugate where two photoactive units are covalently linked is found to be different (Fig. 1d). Under excitation at $460 \mathrm{~nm}, \mathbf{B C h l}-\mathbf{N I}$ demonstrates only the characteristic band of bacteriochlorin, whereas naphthalimide fluorescence is completely quenched. This observation implies that in the conjugate, efficient energy transfer from the naphthalimide to bacteriochlorin fragment may occur. To obtain deeper insight into the nature of processes in the excited state of the BChl-NI molecule we further studied transient absorption (TRABS) spectra of this system.

\section{Transient absorption spectroscopy}

A representative result of a pump-probe experiment for BChl-NI, i.e. a map of absorbance changes after the laser pulse in delaywavelength coordinates is displayed in Fig. 2a. The excitation of 

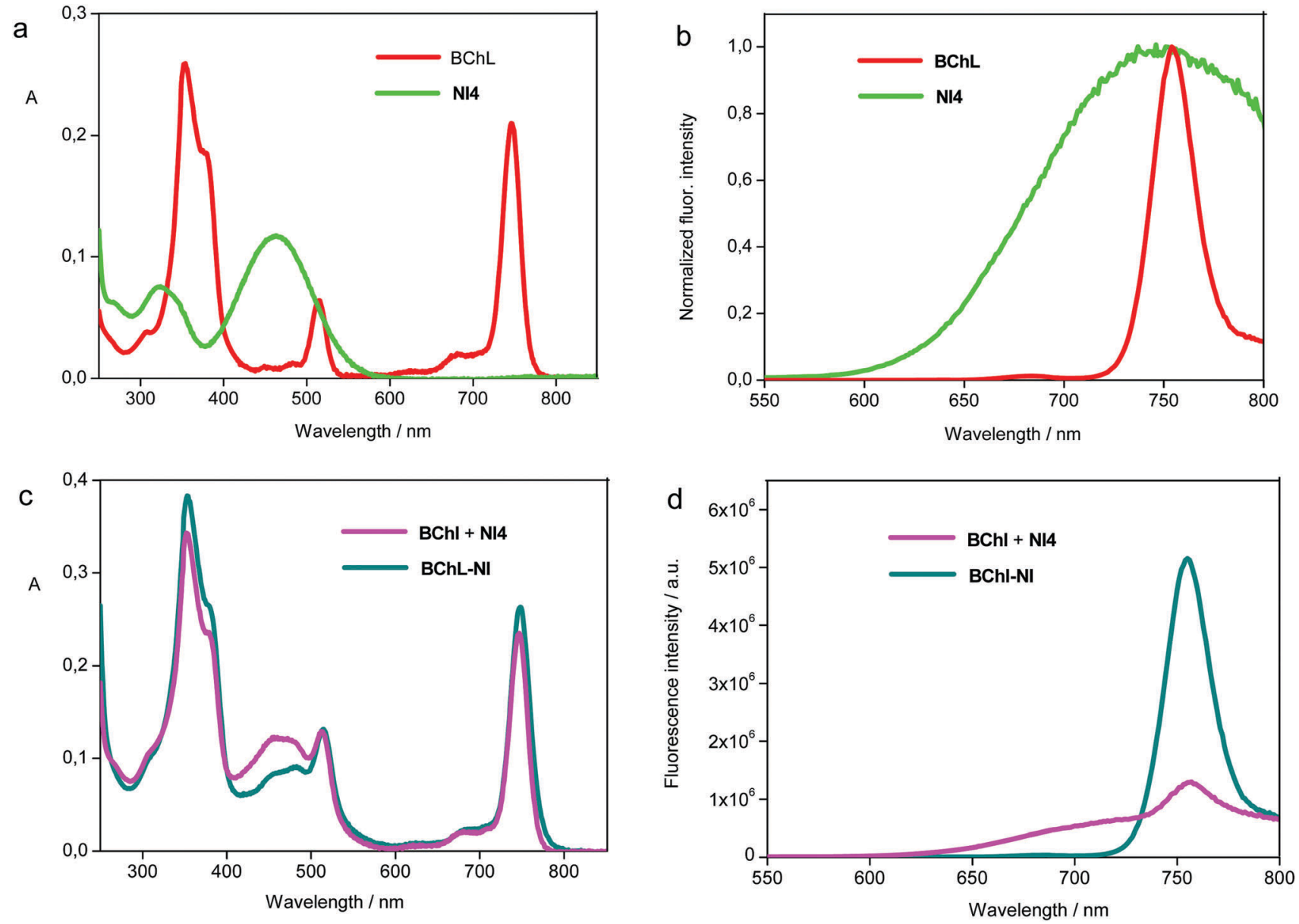

Fig. 1 UV/Vis absorption ( $a$ and $c$ ) and fluorescence emission ( $b$ and d) spectra of compounds BChl, NI4, BChl-NI and an equimolar mixture of BChl and NI4 (denoted as "BChl + NI4") in acetonitrile. The excitation wavelength is $460 \mathrm{~nm}$ for NI4, BChl-NI, BChl + NI4 and $515 \mathrm{~nm}$ for BChl. Concentration of all compounds $4.7 \times 10^{6} \mathrm{M}$.

Table 1 Photophysical characteristics of compounds $\mathbf{B C h l}, \mathbf{N I}$ and $\mathbf{B C h l}-\mathbf{N I}$ in acetonitrile ${ }^{a}$

\begin{tabular}{|c|c|c|c|c|c|c|c|c|c|}
\hline & \multirow[b]{3}{*}{$\lambda_{\text {max }}^{\mathrm{abs}} / \mathrm{nm}$} & \multirow[b]{3}{*}{$\lambda_{\max }^{\mathrm{fl}}\left(\lambda_{\mathrm{ex}}\right) / \mathrm{nm}$} & \multirow[b]{3}{*}{$\varphi^{\mathrm{fl}}$} & \multicolumn{4}{|c|}{ Intramolecular RET in BChl NI } & \multirow[b]{3}{*}{$\Phi_{\text {RET2 }}$} & \multirow[b]{3}{*}{$\Phi_{\Delta}\left(\lambda_{\mathrm{ex}} / \mathrm{nm}\right)$} \\
\hline & & & & \multicolumn{2}{|c|}{ Förster theory } & \multicolumn{2}{|l|}{ Experiment } & & \\
\hline & & & & $k_{\mathrm{RET} 1} / \mathrm{s}^{1}$ & $\Phi_{\mathrm{RET} 1}$ & $k_{\mathrm{RET} 1} / \mathrm{s}^{1}$ & $\Phi_{\mathrm{RET} 1}$ & & \\
\hline NI4 & 462 & $743(460)$ & 0.032 & & & & & & \\
\hline BChl & $353 ; 515 ; 746$ & $755(515)$ & 0.016 & & & & & & $0.79(510)$ \\
\hline BChl NI & $354 ; 481 ; 515 ; 747$ & $755(460)$ & 0.023 & $0.57 \times 10^{12}$ & 0.995 & $1.89 \times 10^{12}$ & 0.999 & 0.981 & $0.82(510)$ \\
\hline
\end{tabular}

the naphthalimide chromophore with $470 \mathrm{~nm}$ light produced a negative signal at $750 \mathrm{~nm}$. In accordance with the position of the long wavelength absorption band of BChl (Fig. 1a), this signal can be ascribed to the ground state bleaching of bacteriochlorin in the conjugate. $\$$ Another feature of the TRABS map shown in Fig. 1a is a broad positive band stretching from 500 to $680 \mathrm{~nm}$.

\$ Apparently, the contribution of stimulated emission to the negative signal at $750 \mathrm{~nm}$ is relatively small, because of a high value of radiative lifetime $\left(\tau_{\mathrm{r}}\right)$ of bacterioclorin. Radiative lifetime is known to be the ratio of excited singlet state lifetime to the fluorescence quantum yield. From the data presented in Fig. 2 and Table $1, \tau_{\mathrm{r}}=2 \mathrm{~ns} / 0.016=125 \mathrm{~ns}$. Such a high $\tau_{\mathrm{r}}$ value explains low radiative rate constant $\left(k_{\mathrm{r}}=1 / \tau_{\mathrm{r}}\right)$ and low propability of stimulated emission as a result.
Probably, this spectral region covers the area where absorption signals of singlet $\left(\mathrm{S}_{1}\right)$ states of both chromophores are located. One can also see that the appearance of a negative band on a time scale occurs not immediately after the excitation pulse and proceeds with a characteristic time of $0.53 \mathrm{ps}$ as obtained from the TRABS time profile (Fig. 2b).§ Hence, the initially formed

$\S$ Characteristic time $\tau_{2}=4.1$ ps shown in Fig. $2 \mathrm{~b}$ describes the relaxation of the singlet excited state of bacteriochlorin. Probably, the positive signal of $\mathrm{S}_{1} \rightarrow \mathrm{S}_{n}$ absorption has non zero intensity at around $750 \mathrm{~nm}$ which tends to decrease upon increasing time delay. Thus, the negative signal at $750 \mathrm{~nm}$ is becoming more and more negative even after the fast process with $\tau_{1}=0.53 \mathrm{ps}$ is completed. 

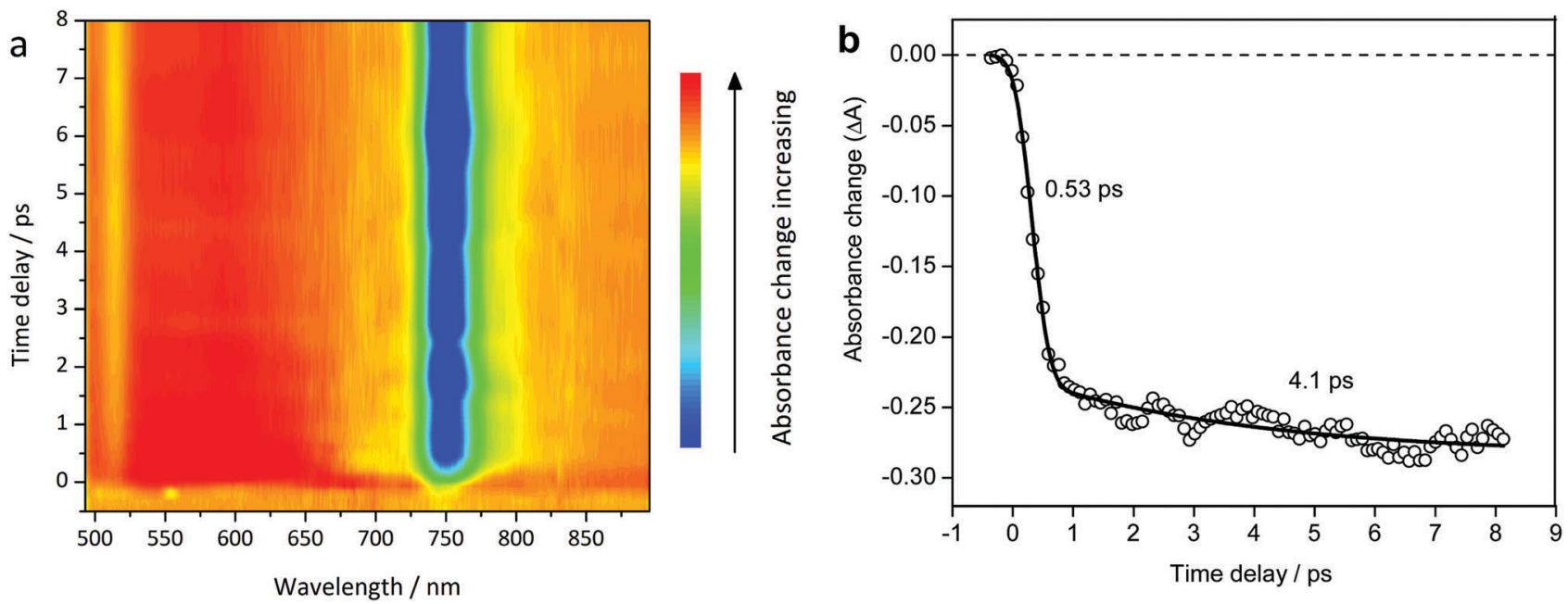

Fig. 2 TRABS spectral map with subpicosecond time resolution (a) and TRABS kinetics at $750 \mathrm{~nm}$ (b) of BChl-NI in acetonitrile. Excitation wavelength $470 \mathrm{~nm}$.

naphthalimide excited state should participate in a kind of fast non-radiative process more likely to be the resonance energy transfer (RET). The rate constant of RET $\left(k_{\text {RET1 }}\right)$ can be estimated from the known characteristic time as $1 / 0.53 \times 10^{-12} \mathrm{~s}$ (see Table 1 for the value of $k_{\mathrm{RET} 1}$ ). Quantum efficiency of intramolecular RET $\left(\Phi_{\mathrm{RET} 1}\right)$ is expressed as the ratio of $k_{\mathrm{RET} 1}$ to the sum of rate constants of all other possible processes in the $\mathrm{S}_{1}$ state of a donor:

$$
\Phi_{\mathrm{RET} 1}=\frac{k_{\mathrm{RET} 1}}{k_{\mathrm{RET} 1}+k_{\mathrm{r}}+k_{\mathrm{nr}}}=\frac{k_{\mathrm{RET} 1}}{k_{\mathrm{RET} 1}+\tau_{\mathrm{D}, 0}-1}
$$

In eqn (3) $k_{\mathrm{r}}$ is the radiative rate constant of the naphthalimide chromophore, and $k_{\mathrm{nr}}$ describes its non-radiative relaxation which is not related to energy transfer. To estimate the sum $\left(k_{\mathrm{r}}+k_{\mathrm{nr}}\right)$ we used the value inversely proportional to the fluorescence lifetime of compound NI4 $\left(\tau_{\mathrm{D}, 0}=0.38 \mathrm{~ns}\right),{ }^{44}$ where the RET process is not realized. The obtained value of $\Phi_{\mathrm{RET} 1}$ was found to be close to unity (Table 1) indicating a highly efficient RET in the BChl-NI conjugate. Additionally, calculations of $k_{\mathrm{RET} 1}$ and $\Phi_{\mathrm{RET} 1}$ by the Förster model ${ }^{58}$ testify to the same result. The details of these calculations are shown in the ESI. $\dagger$

Further evolution of TRABS signals of the bacteriochlorin unit in BChl-NI can be followed by using the spectral map with nanosecond resolution (Fig. 3a). The horizontal cuts of this map at a given time delay give us the TRABS spectra at these delays. The spectrum immediately after excitation is shown in blue in Fig. $3 \mathrm{~b}$. In this spectrum, we can see a broad absorption band of the bacteriochlorin singlet state (several $\mathrm{S}_{1} \rightarrow \mathrm{S}_{n}$ transitions could contribute) in the range of $400-650 \mathrm{~nm}$ formed as a result of energy transfer and negative features at 515 and $700 \mathrm{~nm}$ corresponding to the ground state bleaching. Kinetics of absorption at $600 \mathrm{~nm}$ (Fig. 3c) clearly shows that the $\mathrm{S}_{1}$ state relaxes within $2 \mathrm{~ns}$ at which it converts to some long-lived species presumably regarded as triplets. Thus, the

I Energy transfer process is not visible in this map; it can be perceived with the aid of the subpicosecond experiment described above. spectrum after $40 \mathrm{~ns}$ (Fig. 3b, red line) shows us the absorption of the $\mathrm{T}_{1}$ state.

The lifetime of the bacteriochlorin triplet state was found to be dramatically affected by the presence of oxygen. Whereas the degased solution exhibited single exponential decay with a time constant of $19 \mu \mathrm{s}\left(\tau_{\mathrm{T}}\right)$, in the case of an air saturated sample, the observed lifetime was $0.355 \mu \mathrm{s}\left(\tau_{\mathrm{T}}^{\mathrm{O}_{2}}\right)$ (Fig. 3c and d). Considering the difference in $\tau_{\mathrm{T}}$ and $\tau_{\mathrm{T}}^{\mathrm{O}_{2}}$ values, one can conclude that the excitation energy is transferred from the PS unit to molecular oxygen upon collisions which leads to the formation of ${ }^{1} \mathrm{O}_{2}$ and PS in the ground state. The efficiency of this process given as $\Phi_{\mathrm{RET} 2}$ was calculated by eqn (4).

$$
\Phi_{\mathrm{RET} 2}=1 \quad \frac{\tau_{\mathrm{T}}^{\mathrm{O}_{2}}}{\tau_{\mathrm{T}}}
$$

As evident from the obtained value of $\Phi_{\text {RET2 }}(0.981$, see Table 1$)$, bacteriochlorin in BChl-NI works as an excellent photosensitizer allowing the generation of ${ }^{1} \mathrm{O}_{2}$ with a high quantum yield.

\section{Photosensitizing activity}

Singlet oxygen $\left({ }^{1} \mathrm{O}_{2}\right)$ is thought to be a key cytotoxic agent in the photodynamic inactivation of living cells. ${ }^{59,60}$ It is formed as a result of energy transfer from the photosensitizer triplet state to molecular oxygen. Photosensitized ${ }^{1} \mathrm{O}_{2}$ formation was studied using 1,3-diphenylisobenzofuran (DPBF) as a singlet oxygen trap. Interaction of DPBF with ${ }^{1} \mathrm{O}_{2}$ is known to be purely chemical, resulting in the formation of colorless endoperoxides. ${ }^{53,54}$ This process causes bleaching of the main maximum of DPBF at $414 \mathrm{~nm}$. Fig. 4 illustrates one of the experiments on photosensitized bleaching of DPBF in a solution of the BChl-NI conjugate in acetone under illumination with green $(510 \mathrm{~nm})$ light which is absorbed by both chromophores. Rapid photobleaching of DPBF was also detected in the solution of free bacteriochlorin BChl (Fig. S24, ESI†). This observation is consistent with the results of previous studies which showed that metal-free bacteriochlorins efficiently photosensitized 

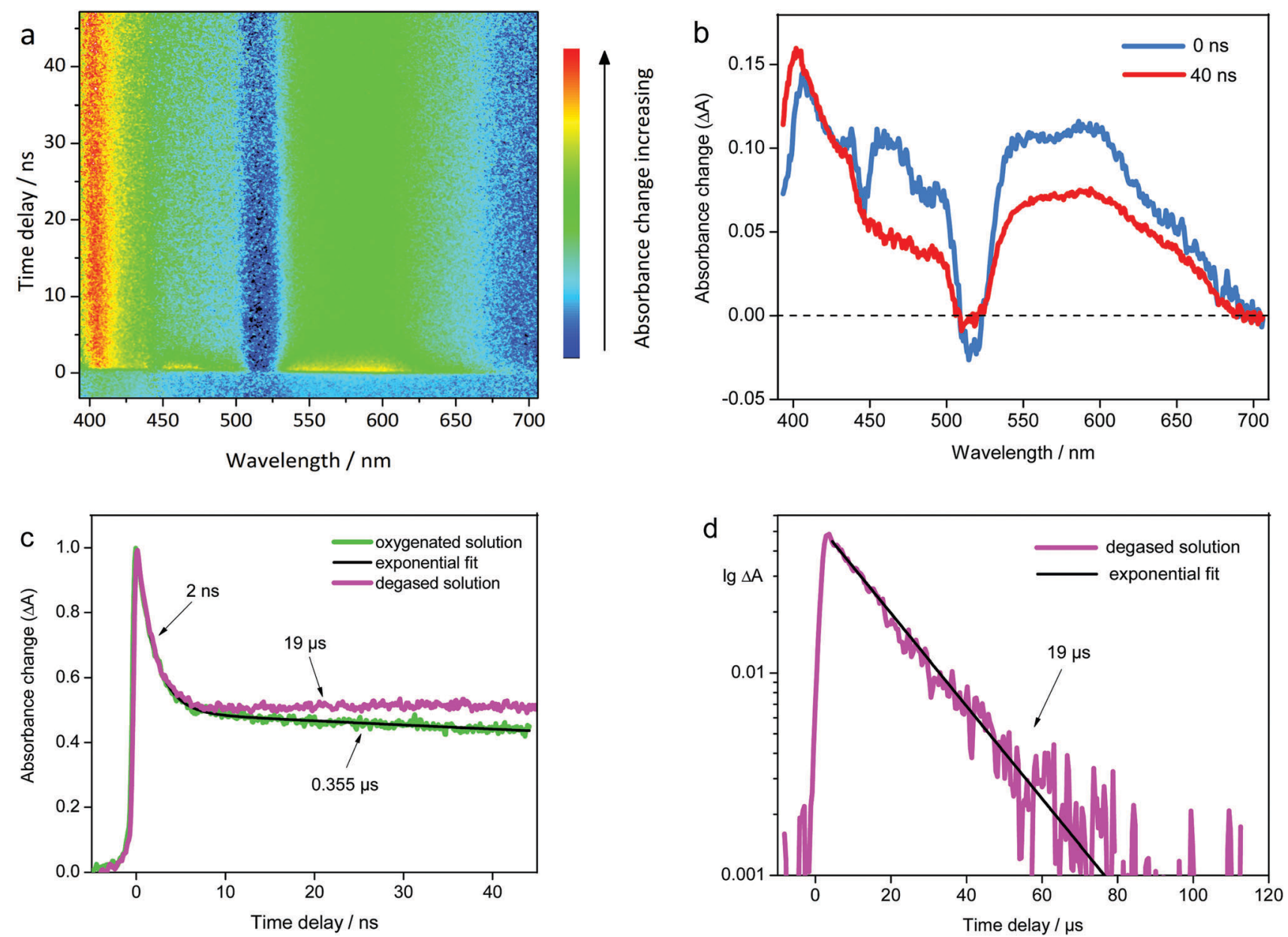

Fig. 3 TRABS spectral map (a) with nanosecond time resolution, TRABS spectra at different time delays (b) and TRABS kinetic curves at $600 \mathrm{~nm}$ in the presence and absence of oxygen ( $c$ and d) of BChl-NI in acetonitrile. Excitation wavelength $440 \mathrm{~nm}$. Spectral map has a negative perturbed signal at $440 \mathrm{~nm}$ induced by the filter rejecting this wavelength.

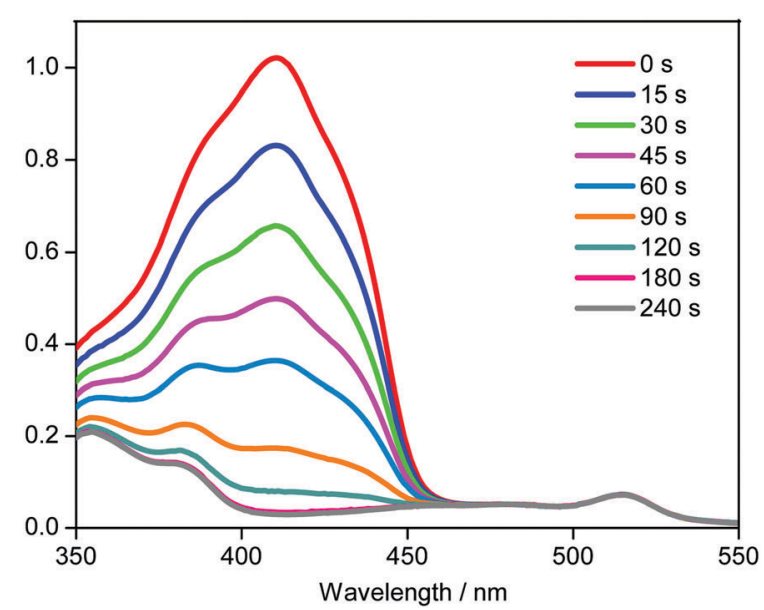

Fig. 4 Changes in the UV/Vis absorption spectrum of a mixed solution containing the BChl-NI conjugate $\left(2.6 \times 10^{6} \mathrm{M}\right)$ and $\operatorname{DPBF}\left(4.0 \times 10^{5} \mathrm{M}\right)$ in acetone upon irradiation at $510 \mathrm{~nm}$.

singlet oxygen formation in air saturated solutions. ${ }^{61,62}$ In solution of the free naphthalimide dye, photobleaching of the trap was not found (Fig. S25, ESI $\dagger$ ). The quantum yields of singlet oxygen production of BChl and BChl-NI under excitation at $510 \mathrm{~nm}$ were found to be 0.79 and 0.82 , respectively (Table 1 ). Such close values indicate that photosensitizing activity of the naphthalimide dye in the conjugate is, apparently, caused by efficient energy transfer from the dye to the bacteriochlorin, which is in good agreement with the above time-resolved studies of BChl-NI, and the presence of the naphthalimide fragment in BChl-NI does not decrease the ability of the PS core to generate ${ }^{1} \mathrm{O}_{2}$.

\section{In vitro studies of the BChl-NI conjugate}

As confirmed by confocal microspectroscopy and confocal laser scanning microscopy, the conjugate penetrates into cancer A549 cells (Fig. 5 and 6). Intracellular fluorescence spectra of BChl-NI were recorded by confocal microspectroscopy with the $488 \mathrm{~nm}$ excitation wavelength, which fitted well to the absorption band of the NI moiety of the conjugate. A typical intracellular emission spectrum of BChl-NI is shown in Fig. 5e. Its shape and long-wavelength maximum $(757 \mathrm{~nm})$ correspond to the fluorescence of the bacteriochlorin moiety. Intense illumination of a cell with the $488 \mathrm{~nm}$ light leads to the changes in the 

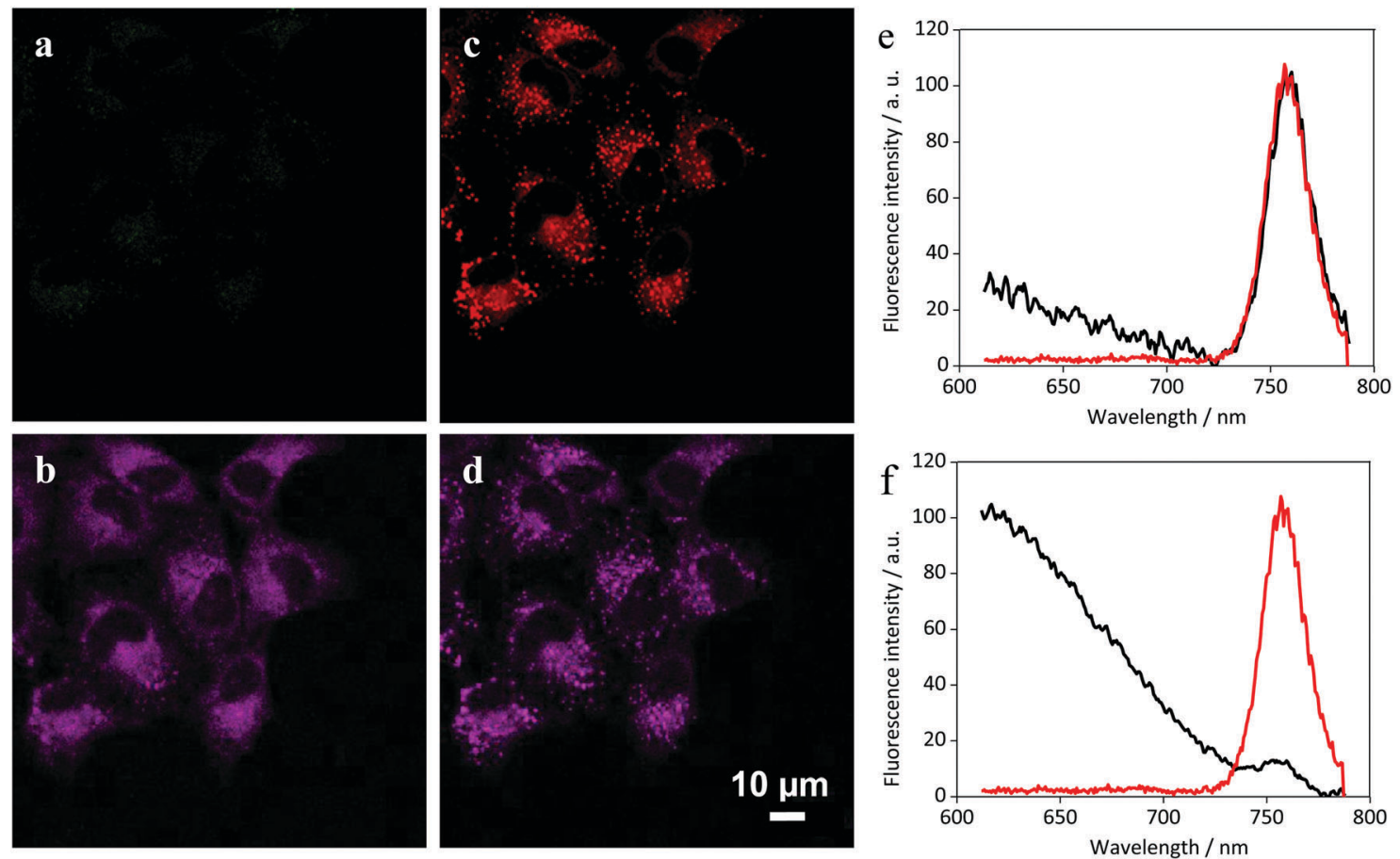

Fig. 5 Intracellular distribution of BChl-NI fluorescence in A549 cells. Distribution of fluorescence in the $550650 \mathrm{~nm}$ (a and c) and >730 nm (b and d) ranges at the low power $488 \mathrm{~nm}$ excitation before ( $\mathrm{a}$ and $\mathrm{b}$ ) and after ( $\mathrm{c}$ and $\mathrm{d}$ ) the high power prolonged illumination (photobleaching) of cells with the $488 \mathrm{~nm}$ wavelength. (e and f) Examples of intracellular fluorescence spectra of BChl-NI (black line) at the $488 \mathrm{~nm}$ excitation before (e) and after (f) the high power prolonged illumination (photobleaching) of cells. Red line fluorescence spectrum of Bchl in $1 \%$ Chremophor EL solution. Spectra are normalized to the highest intensity. Cells were incubated with $2 \mu \mathrm{M}$ of $\mathbf{B C h l}-\mathbf{N I}$ for $3 \mathrm{~h}$.

intracellular fluorescence spectra of BChl-NI: a band with the $757 \mathrm{~nm}$ maximum disappears due to photobleaching of the acceptor (BChl), and donor (NI) fluorescence is restored, which has a maximum at $c a .600 \mathrm{~nm}$ (Fig. 5f). These changes confirm RET between NI and BChl chromophores in cells and show that the polarity of the cellular microenvironment is similar to the
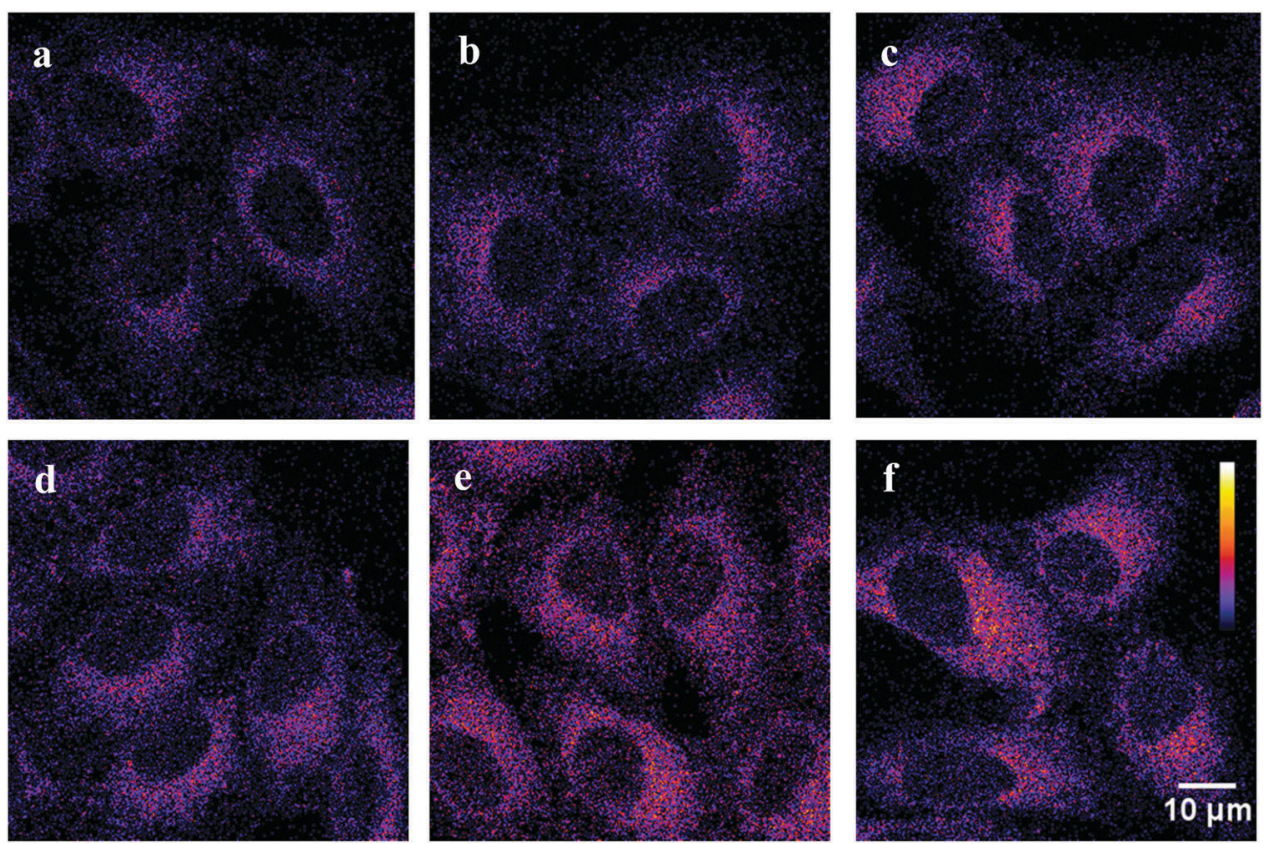

Fig. 6 Intracellular accumulation of BChl-NI in A549 cells. Confocal fluorescent images describing the intracellular distribution of the conjugate based on the bacteriochlorin fluorescence (exitation $514 \mathrm{~nm}$, emission $>730 \mathrm{~nm}$ ). Cells were incubated with 2 ( $\mathrm{a}$ and d), 4 (b and e), 8 (c and f) $\mu \mathrm{M}$ conjugate for $1 \mathrm{~h}(\mathrm{a}$ c) or $3 \mathrm{~h}(\mathrm{~d}$ f). 

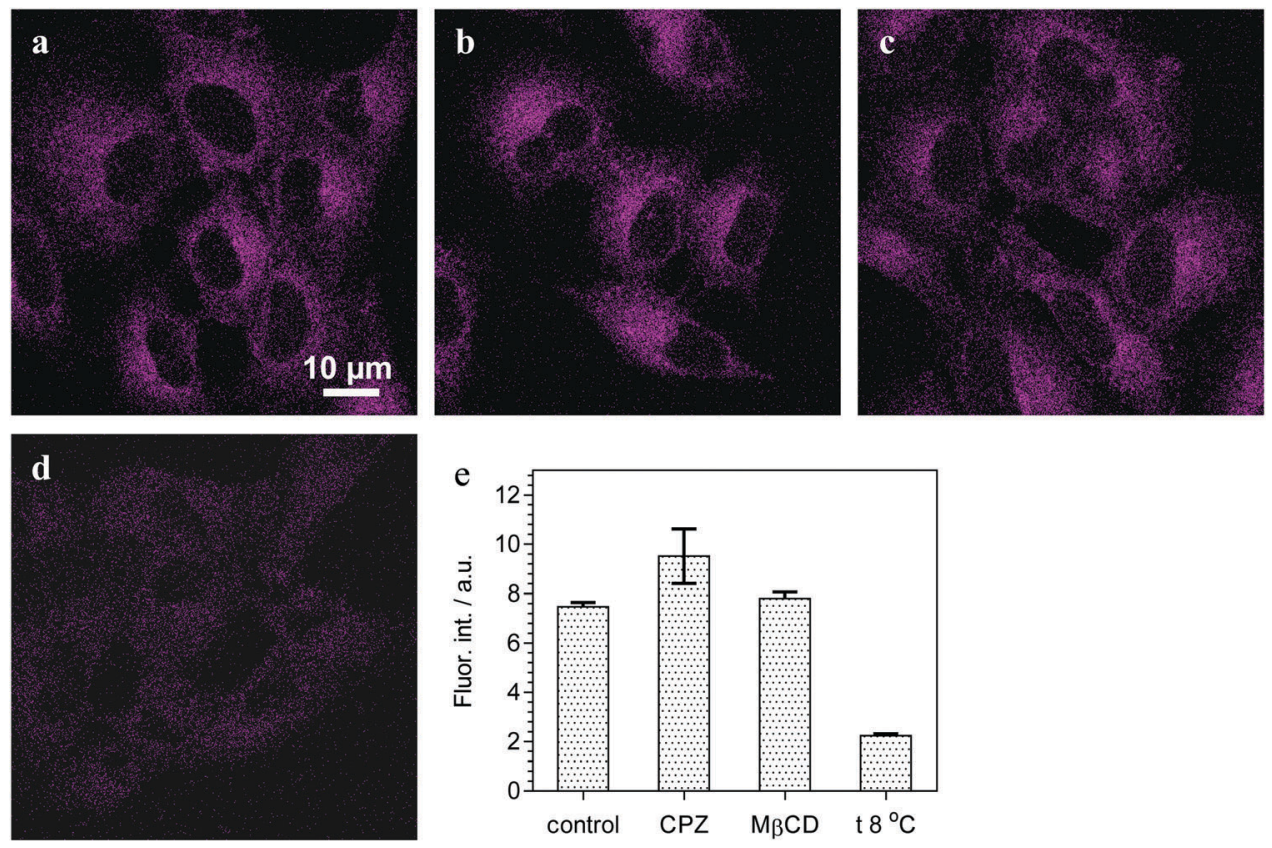

Fig. 7 Study of mechanisms of intracellular penetration of BChl-NI. (a d) Confocal fluorescent images showing the intracellular distribution of BChl-NI in control cells (a), cells pre incubated with $30 \mu \mathrm{M}$ chlorpromazine (b) or $4 \mathrm{mM}$ methyl $\beta$ cyclodextrin for 30 min (c) or in the cells at $8{ }^{\circ} \mathrm{C}$ (d). (e) Comparison of average intracellular fluorescence intensities of $\mathbf{B C h l}-\mathbf{N I}$ in incubation regimes depicted in (a d): $C P Z, M B C D \quad$ treatment with chlorpromazine or methyl $\beta$ cyclodextrin, respectively. Cells were incubated with $4 \mu \mathrm{M} \mathrm{BChl-NI} \mathrm{for} 70$ min at $37^{\circ} \mathrm{C}(\mathrm{a} \quad \mathrm{C})$ or $8{ }^{\circ} \mathrm{C}$ (d).

polarity of diethyl ether solution $(\varepsilon=4.3)$, where the NI chromophore has a fluorescence maximum at $608 \mathrm{~nm}$. $\|^{44}$

In agreement with microspectroscopy studies, confocal laser scanning microscopy reveals intracellular fluorescence of BChl-NI in the range of $730 \mathrm{~nm}$ and longer wavelengths (at the excitation of 488 or $514 \mathrm{~nm}$ ) and the absence of fluorescence in the 500-650 nm range (Fig. 5a and b). As clearly seen (Fig. 5b and 6), the conjugate accumulates in the cytoplasm of A549 cells and does not penetrate into the nucleus. In the cytoplasm, Bchl-NI has diffuse distribution. The pattern of intracellular distribution is similar at different extracellular concentrations of BChl-NI and different incubation times of cells with the conjugate (Fig. 6). An increase in the extracellular concentration of the conjugate from 2 to $8 \mu \mathrm{M}$ and incubation time from 1 to $3 \mathrm{~h}$ increases moderately intracellular fluorescence that indicates saturation of intracellular accumulation of BChl-NI at concentrations higher than $4 \mu \mathrm{M}$ and an incubation time of $3 \mathrm{~h}$.

Intense prolonged illumination of cells with $488 \mathrm{~nm}$ or $514 \mathrm{~nm}$ light leads to the appearance of fluorescence in the 500-650 nm range due to photobleaching of the BChl chromophore. In the course of photobleaching, the distribution of

\footnotetext{
|| Similar blue shift of the naphthalimide emission band was also observed in rabbit blood serum. However, RET between NI and BChl chromophores remains highly efficient as it is in $\mathrm{CH}_{3} \mathrm{CN}$ (the solvent we used for the photophysical studies, $\varepsilon=37.5$ ). This was demonstrated by the comparison of emission spectra of the BChl NI conjugate in rabbit blood serum with the corresponding spectra of an equimolar mixture containing an individual photosensitizer BChl and naphthalimide dye (see the ESI, $\dagger$ Fig. S26).
}

intracellular fluorescence becomes granular (Fig. $5 \mathrm{c}$ and d) as a result of photodynamic (phototoxic) processes induced in cells.

To study the mechanism of BChl-NI penetration into cells, the known inhibitors of clathrin-dependent (chlorpromazine) and caveolae-dependent (methyl- $\beta$-cyclodextrin) endocytosis ${ }^{63}$ were used. It was found that intracellular penetration of BChl-NI was not inhibited, when cells were pre-treated with chlorpromazine (an inhibitor, which induces dissociation of clathrin from a cell surface) (Fig. 7b) or with methyl- $\beta$-cyclodextrin (a compound that depletes plasma membrane cholesterol) (Fig. 7c). Therefore, clathrin-dependent or caveolae-dependent endocytosis

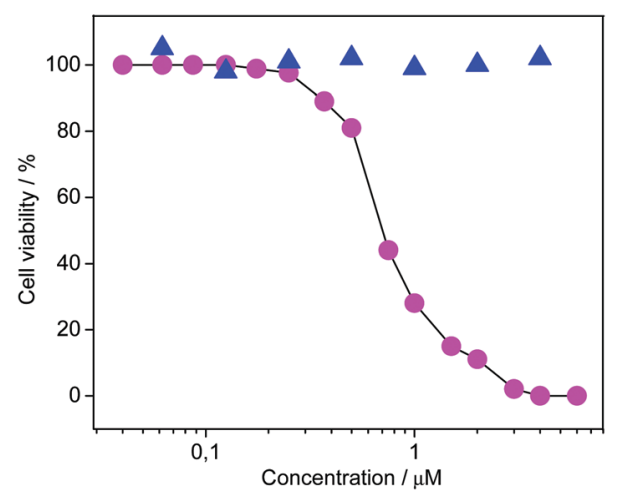

Fig. 8 Concentration dependent survival of A549 cells after photo dynamic treatment with the conjugate (circles). An abscissa is the photo sensitizer concentration in the medium. Cells were incubated with the conjugate for $3 \mathrm{~h}$, irradiated with light, and their survival was determined $3 \mathrm{~h}$ after irradiation. Control cells (triangles) were incubated with the conjugate for $6 \mathrm{~h}$ without irradiation. 

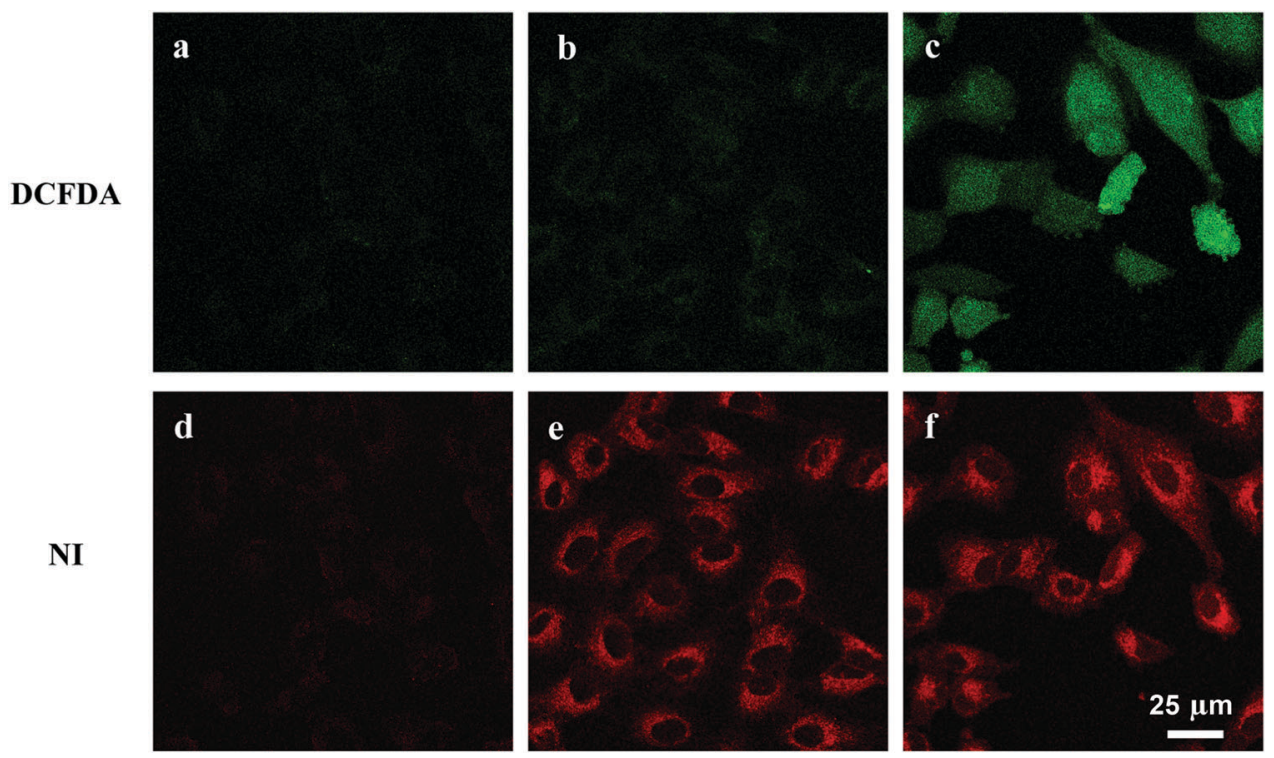

Fig. 9 Verification of light induced ROS formation in cells using DCFDA. Confocal fluorescence images show distribution of DCFDA (a c) and NI moiety ( $\mathrm{d}$ f) fluorescence in the irradiated A549 cells. Fluorescence was excited at $488 \mathrm{~nm}$ and registered in the $500540 \mathrm{~nm}$ (DCFDA, green) and $600650 \mathrm{~nm}$ (NI, red). (a and d) Cells were incubated with DCFDA but without BChl-NI and irradiated with red light. (b and e) Cells were incubated with BChl-NI but without DCFDA and irradiated. (c and f) Cells were incubated with BChl-NI and DCFDA and irradiated.

pathways are not noticeably involved in BChl-NI uptake into A549 cells. A decrease in incubation temperature from 37 to $8{ }^{\circ} \mathrm{C}$ led to a threefold decrease in BChl-NI intracellular accumulation (Fig. 7d and e). This effect can be explained by a passive diffusion of BChl-NI through the plasma membrane, which is affected by a decrease in membrane fluidity at a low temperature.

The studies showed that the BChl-NI conjugate was not toxic for A549 cells at tested concentrations ( $<8 \mu \mathrm{M}$, Fig. 8) without light-induced activation. At the same time, the concentration-dependent killing of cells (Fig. 8) was observed upon irradiation with red light. Under the used conditions, the photodynamic effect was achieved through the excitation of the bacteriochlorin moiety. Conjugate concentrations that provide $90 \%$ and $50 \%$ photoinduced cell death are $0.70 \pm 0.05$ and $0.33 \pm 0.05 \mu \mathrm{M}$, respectively. These data indicate that the conjugate is an active photosensitizer, and its further investigation for anticancer photodyanmic therapy is warranted.

To confirm the formation of reactive oxygen species (ROS) in cells under irradiation, cells were incubated with both DCFDA and BChl-NI and irradiated with red light (Fig. 9). In viable cells, DCFDA undergoes deacetylation to non-fluorescent $2^{\prime}, 7^{\prime}$-dichlorofluorescein. This compound reacts quantitatively with ROS in cells and produces the fluorescent dye $2^{\prime}, 7^{\prime}$-dichlorofluorescein. DCFDA is known to be very reactive with peroxides but can also be oxidized by other ROS. ${ }^{64}$ Bright fluorescence of DCFDA and the NI-moiety was observed in the cytoplasm after irradiation (Fig. 9c and f). The appearance of DCFDA fluorescence indicates ROS generation during irradiation of cells. No fluorescence of DCFDA and NI was detected in control cells without irradiation (data not shown). No fluorescence of DCFDA was observed in cells incubated with DCFDA but without BChl-NI and irradiated (Fig. 9a) thus confirming again that BChl-NI does produce ROS during irradiation with red light.

\section{Conclusions}

In summary, we have prepared a novel bacteriochlorin-naphthalimide conjugate BChl-NI. A steady-state and time-resolved spectroscopic study of BChl-NI in solution has shown that the presence of the NI fragment does not decrease the photosensitizing activity of $\mathbf{B C h l}$; however the fluorescence of naphthalimide is quenched due to efficient resonance energy transfer. In vitro results revealed high photoinduced cytotoxicity and fluorescence imaging capability that can be realized using both chromophores. Far-red absorption and fluorescence of the BChl moiety make this conjugate suitable for photodynamic treatment of deeply located tumors as well as for fluorescence imaging and navigation in vivo. At the same time far-red fluorescence of the conjugate is poorly detectable in cellular studies, since conventional confocal microscopes equipped with photomultiplier-based detection systems have low sensitivity in the 700-900 nm spectral range. Accordingly, photoinduced magenta-to-red ${ }^{* *}$ conversion of fluorescence can facilitate

\footnotetext{
** We used confocal laser scanning microscopy to visualize the intracellular distribution of the BChl NI conjugate. Fluorescence was registered using a highly sensitive avalanche photodiode or a photomultiplier. Both detectors record the intensity of emitted light in each point of a scanned specimen and do not recognize color (wavelength) of detected photons. Color of the image is selected by a scientist using palettes, which are available in software. In order to provide better color reproduction, we chose red color for NI emission in Fig. 5c. Fluorescence of the BChl moiety has wavelengths that are not visible to the human eye. We decided to use dark magenta color for this fluorescence in the presented images.
} 
visualization of the conjugate in cellular studies. Moreover, this color conversion of BChl-NI fluorescence could be a useful indicator of integrity of the photosensitizer moiety during irradiation of cancer cells and can help in optimizing the power and dose of light during photodynamic treatment. Thus, the newly synthesized conjugate BChl-NI is a good candidate for the nextgeneration "bifunctional" photosensitizer allowing PDT and fluorescence diagnostics to be performed.

\section{Conflicts of interest}

There are no conflicts to declare.

\section{Acknowledgements}

O. A. F. thanks RSF project No. 16-13-10226 (synthesis of naphthalimide derivatives, steady-state absorption and fluorescence spectroscopy), M. A. G. thanks RSF project No. 16-13-10092 (synthesis of bacteriochlorin derivatives), G. J. thanks the Région Nouvelle-Aquitaine for financial support (time-resolved optical measurements).

\section{References}

1 J. P. Celli, B. Q. Spring, I. Rizvi, C. L. Evans, K. S. Samkoe, S. Verma, B. W. Pogue and T. Hasan, Chem. Rev., 2010, 110, 2795-2838.

2 P. Agostinis, K. Berg, K. A. Cengel, T. H. Foster, A. W. Girotti, S. O. Gollnick, S. M. Hahn, M. R. Hamblin, A. Juzeniene, D. Kessel, M. Korbelik, J. Moan, P. Mroz, D. Nowis, J. Piette, B. C. Wilson and J. Golab, Ca-Cancer J. Clin., 2011, 61, 250-281.

3 B. W. Henderson and T. J. Dougherty, Photochem. Photobiol., 1992, 55, 145-157.

4 B. W. Henderson, T. J. Dougherty and P. B. Malone, Prog. Clin. Biol. Res., 1984, 170, 601-612.

5 B. W. Henderson and S. O. Gollnick, in CRC Handbook of Organic Photochemistry and Photobiology, ed. W. M. Horspool, F. Lenci, CRC Press LLC, Boca Raton, 2nd edn, 2004.

6 I. J. MacDonald and T. J. Dougherty, J. Porphyrins Phthalocyanines, 2001, 5, 105-129.

7 B. C. Wilson, W. P. Jeeves and D. M. Lowe, Photochem. Photobiol., 1985, 42, 153-162.

8 D. Kessel, Photochem. Photobiol., 1989, 49, 447-452.

9 R. R. Allison, G. H. Downie, R. Cuenca, X.-H. Hu, C. J. Childs and C. H. Sibata, Photodiagn. Photodyn. Ther., 2004, 1, 27-42.

10 S. J. Bakri and P. K. Kaiser, Expert Opin. Pharmacother., 2004, 5, 195-203.

11 M. Huggett, M. Jermyn, A. Gillams, R. Illing, S. Mosse, M. Novelli, E. Kent, S. Bown, T. Hasan and B. Pogue, $B r$. J. Cancer, 2004, 110, 1698-1704.

12 N. C. Gady, R. Granet and V. Sol, Dyes Pigm., 2013, 98, 609-614.

13 N. Patel, P. Pera, P. Joshi, M. Dukh, W. A. Tabaczynski, K. E. Siters, M. Kryman, R. R. Cheruku, F. Durrani,
J. R. Missert, R. Watson, T. Y. Ohulchanskyy, E. C. Tracy, H. Baumann and R. K. Pandey, J. Med. Chem., 2016, 59, 9774-9787.

14 A. Grichine, A. Feofanov, T. Karmakova, N. Kazachkina, E. Pecherskih, R. Yakubovskaya, A. Mironov, M. EgretCharlier and P. Vigny, Photochem. Photobiol., 2001, 73, 267-277.

15 A. Feofanov, G. Sharonov, A. Grichine, T. Karmakova, A. Pljutinskaya, V. Lebedeva, R. Ruziyev, R. Yakubovskaya, A. Mironov, M. Refregier, J.-C. Maurizot and P. Vigny, Photochem. Photobiol., 2004, 79, 172-188.

16 G. V. Sharonov, T. A. Karmakova, R. Kassies, A. D. Pljutinskaya, M. A. Grin, M. Refregiers, R. I. Yakubovskaya, A. F. Mironov, J.-C. Maurizot, P. Vigny, C. Otto and A. V. Feofanov, Free Radical Biol. Med., 2006, 40, 407-419.

17 T. Karmakova, A. Feofanov, A. Pankratov, N. Kazachkina, A. Nazarova, R. Yakubovskaya, V. Lebedeva, R. Ruziyev, A. Mironov, J.-C. Maurizot and P. Vigny, J. Photochem. Photobiol., B, 2006, 82, 28-36.

18 M. P. A. Williams, M. Ethirajan, K. Ohkubo, P. Chen, P. Pera, J. Morgan, W. H. White III, M. Shibata, S. Fukuzumi, K. M. Kadish and R. K. Pandey, Bioconjugate Chem., 2011, 22, 2283-2295.

19 N. S. James, T. Y. Ohulchanskyy, Y. Chen, P. Joshi, X. Zheng, L. N. Goswami and R. K. Pandey, Theranostics, 2013, 3, 703-718.

20 N. S. James, P. Joshi, T. Y. Ohulchanskyy, Y. Chen, W. Tabaczynski, F. Durrani, M. Shibata and R. K. Pandey, Eur. J. Med. Chem., 2016, 122, 770-785.

21 P. A. Panchenko, A. N. Sergeeva, O. A. Fedorova, Yu. V. Fedorov, R. I. Reshetnikov, A. E. Schelkunova, M. A. Grin, A. F. Mironov and G. Jonusauskas, J. Photochem. Photobiol., B, 2014, 133, 140-144.

22 M. A. Grin, P. V. Toukach, V. B. Tsvetkov, R. I. Reshetnikov, O. V. Kharitonova, A. S. Kozlov, A. A. Krasnovsky and A. F. Mironov, Dyes Pigm., 2015, 121, 21-29.

23 N. S. James, Y. Chen, P. Joshi, T. Y. Ohulchanskyy, M. Ethirajan, M. Henary, L. Strekowsk and R. K. Pandey, Theranostics, 2013, 3, 692-702.

24 H. Yanik, M. Göksel, S. Yeşilot and M. Durmuş, Tetrahedron Lett., 2016, 57, 2922-2926.

25 C. Göl, M. Malkoç, S. Yeşilot and M. Durmuş, Dyes Pigm., 2014, 111, 81-90.

26 V. M. Derkacheva, S. A. Mikhalenko, L. I. Solov'eva, V. I. Alekseeva, L. E. Marinina, L. P. Savina, A. V. Butenin and E. A. Luk'yanets, Russ. J. Gen. Chem., 2007, 6, 1117-1125.

27 N. Kuznetsova, D. Makarov, V. Derkacheva, L. Savvina, V. Alerseeva, L. Marinina, L. Slivka, O. Kaliya and E. Lukyanets, J. Photochem. Photobiol., A, 2008, 200, 161-168.

28 L. G. F. Patrick and A. Whiting, Dyes Pigm., 2002, 52, 137-143. 29 I. Grabchev and R. Betcheva, J. Photochem. Photobiol., A, 2001, 142, 73-78.

30 L. G. F. Patrick and A. Whiting, Dyes Pigm., 2002, 55, 123-132.

31 E. Martin, R. Weigand and A. Pardo, J. Lumin., 1996, 68, 157-164. 
32 W. Zhu, M. Hu, R. Yao and H. Tian, J. Photochem. Photobiol., A, 2003, 154, 169-177.

33 G. Tu, Q. Zhou, Y. Cheng, Y. Geng, L. Wang, D. Ma, X. Jing and F. Wang, Synth. Met., 2005, 152, 233-236.

34 C. Coya, R. Blanco, R. Juárez, R. Gómez, R. Martínez, A. de Andrés, Á. L. Álvarez, C. Zaldo, M. M. Ramos, A. de la Peña, C. Seoane and J. L. Segura, Eur. Polym. J., 2010, 46, 1778-1789.

35 L. Song, E. A. Jares-Erijman and T. M. Jovin, J. Photochem. Photobiol., A, 2002, 150, 177-185.

36 X. Meng, W. Zhu, Q. Zhang, Y. Feng, W. Tan and H. Tian, J. Phys. Chem. B, 2008, 112, 15636-15645.

37 O. A. Fedorova, P. A. Panchenko, Y. V. Fedorov, F. G. Erko, J. Berthet and S. Delbaere, J. Photochem. Photobiol., A, 2015, 303-304, 28-35.

38 P. A. Panchenko, O. A. Fedorova and Y. V. Fedorov, Russ. Chem. Rev., 2014, 83, 155-182.

39 R. M. Duke, E. B. Veale, F. M. Pfeffer, P. E. Kruger and T. Gunnlaugsson, Chem. Soc. Rev., 2010, 39, 3936-3953.

40 Z. Xu, J. Yoon and D. R. Spring, Chem. Soc. Rev., 2010, 39, 1996-2006.

41 Z. Xu, X. Qian, J. Cui and R. Zhang, Tetrahedron, 2006, 62, 10117-10122.

42 K. Kawai, K. Kawabata, S. Tojo and T. Majima, Bioorg. Med. Chem. Lett., 2002, 12, 2363-2366.

43 X. Qian, Z. Li and Q. Yang, Bioorg. Med. Chem. Lett., 2007, 15, 6846-6851.

44 P. A. Panchenko, A. N. Arkhipova, O. A. Fedorova, Yu. V. Fedorov, M. A. Zakharko, D. E. Arkhipov and G. Jonusauskas, Phys. Chem. Chem. Phys., 2017, 19, 1244-1256.

45 P. A. Panchenko, A. N. Arkhipova, M. A. Zakharko, G. Jonusauskas, Yu. V. Fedorov and O. A. Fedorova, Russ. Chem. Bull., 2016, 65, 2444-2451.

46 A. N. Arkhipova, P. A. Panchenko, Yu. V. Fedorov and O. A. Fedorova, Mendeleev Commun., 2017, 27, 53-55.

47 A. Scherz, Y. Solomon, A. Brandis and H. Scheer, Pat., WO00/33833, 2000.
48 G. Zheng, B. Chance and J. D. Glickson, Pat., WO2006/073419 A2, 2006.

49 J. Zhou, H. Liu, B. Jin, X. Liu, H. Fub and D. Shangguan, J. Mater. Chem. C, 2013, 1, 4427-4436.

50 H.-H. Lin, Y.-Ch. Chan, J.-W. Chen and C.-C. Chang, J. Mater. Chem., 2011, 21, 3170-3177.

51 S. Nad, M. Kumbhakar and H. Pal, J. Phys. Chem. A, 2003, 107, 4808-4816.

52 C. L. Renschler and L. A. Harrah, Anal. Chem., 1983, 55, 798-800.

53 A. A. Krasnovsky Jr., A. S. Kozlov and Y. V. Roumbal, Photochem. Photobiol. Sci., 2012, 11, 988-997.

54 F. Wilkinson, W. P. Helman and A. B. Ross, J. Phys. Chem. Ref. Data, 1993, 22, 113-262.

55 A. V. Feofanov, A. I. Nazarova, T. A. Karmakova, A. D. Pliutinskaia, A. I. Grishin, R. I. Yakubovskaya, V. S. Lebedeva, R. D. Ruziev, A. F. Mironov, J. C. Maurizot and P. Vigny, Russ. J. Bioorg. Chem., 2004, 30, 374-384.

56 A. V. Efremenko, A. A. Ignatova, A. A. Borsheva, M. A. Grin, V. I. Bregadze, I. B. Sivaev, A. F. Mironov and A. V. Feofanov, Photochem. Photobiol. Sci., 2012, 11, 645-652.

57 A. A. Ignatova, A. S. Maslova, M. P. Kirpichnikov and A. V. Feofanov, Russ. J. Bioorg. Chem., 2009, 35, 746-751.

58 J. R. Lakowicz, Principles of Fluorescence Spectroscopy, Springer, New York, USA, 2006.

59 T. J. Dougherty, C. Gomer, B. Henderson, G. Jori and D. Kessel, J. Natl. Cancer Inst., 1998, 90, 889-905.

60 A. A. Krasnovsky Jr., Singlet oxygen and primary mechanisms of photodynamic therapy and photodynamic diseases, Photodynamic therapy at the cellular level, Research Signpost, Trivandrum-695 023, 2007, pp. 17-62.

61 A. A. Krasnovsky Jr., Photochem. Photobiol., 1979, 29, 29-36.

62 S. Y. Egorov and A. A. Krasnovsky Jr., Proc. SPIE, 1990, 1403, 611-621.

63 A. I. Ivanov, Methods Mol. Biol., 2008, 440, 15-33.

64 C. P. LeBel, H. Ischiropoulos and S. C. Bondy, Chem. Res. Toxicol., 1992, 5, 227-231. 